\title{
TUTELA DOS BENS IMÓVEIS PÚBLICOS E A SALVAGUARDA DAS GARANTIAS CONSTITUCIONAIS FUNDAMENTAIS
}

\author{
GUARANTEE OF PUBLIC PROPERTY AND THE PROTECTION OF \\ FUNDAMENTAL CONSTITUTIONAL GUARANTEES
}

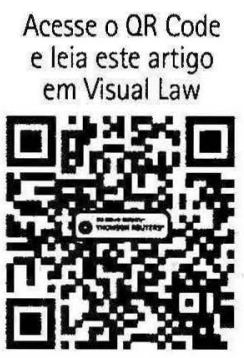

Acesse o QR Code e leia este artigo em Visual Law

ÁrEA DO DIRETO: Administrativo

Resumo: Questão relevante do ponto de vista dos direitos fundamentais é a tutela dos bens imóveis públicos em face das garantias constitucionais fundamentais. 0 presente artigo objetiva analisar quando, diante da turbação dos bens imóveis, admite-se que haja atuação do Estado com autoexecutoriedade, e quando, por outro lado, se excepciona tal hipótese, sendo recomendável a salvaguarda das garantias constitucionais em conflito por meio da intervenção jurisdicional. Espera-se contribuir para a reflexăo desta forma de equacionamento de conflitos sociais, diante de uma visão de Estado preocupada
IRENe PatrícIa Nohara Livre-docente em Direito Administrativo (USP). Doutora e Mestre em Direito do Estado pela Faculdade de Direito da USP. Professora da Universidade Presbiteriana Mackenzie. ORCID: [orcid.org/0000-0002-3182-2803]. irene.nohara@uol.com.br

\section{Hugo von Ancken Erdmann Amoroso}

Mestre em Direito Político e Econômico e pós-graduado em Direito Civil, ambos pela Universidade Presbiteriana Mackenzie.

ORCID: [orcid.org/0000-0001-9810-9669]. hugo@vonanckenguidolin.com.br

Recebido em: 07.08 .2020

Aprovado em: 10.02.2021 DOI: [doi.org/10.48143/rdai.18.ipn] 
com preservação da dignidade humana quando da tutela do patrimônio público.

Palavras-chave: Bens públicos - Proteção possessória - Garantias Constitucionais.

Kerwords: Public property - Possessory protection - Constitutional Guarantees.

Sumário: 1. Introdução. 2. Regime jurídico dos bens públicos. 3. A atuação administrativa diante da ameaça, turbação e esbulho possessórios praticados por particulares contra os bens públicos (afetados ou desafetados). 3.1. Circunstâncias de invocação dos interditos. 3.2. Limites e possibilidades do poder de policia dos bens públicos. 3.3. Defesa dos bens públicos via poder de policia autoexecutório. 3.4. Desforço imediato na defesa dos bens públicos na jurisprudência dos Tribunais Superiores. 3.5. Jurisdição enquanto guardiã das garantias constitucionais: tutela jurisdicional enquanto solução aos conflitos sociais existentes. 3.6. 0 tratamento dado ao tema pela I Jornada de Direito Administrativo do ConseIho da Justiça Federal. 4. Conclusão. 5. Referências.

\section{INTRODUÇÃO}

É frequente atualmente que os imóveis públicos, sejam eles escolas, universidades, prédios públicos e assembleias legislativas, sejam tomados diante de inúmeras situações de reivindicações de distintos grupos, que, por vezes, impedem o uso afetado desses bens à consecução de suas finalidades. Há, ainda, a situação das ocupaçôes pela população de áreas de preservação ambiental e de terras devolutas, hipótese em que entram em conflito a discussão sobre a moradia e outros bens jurídicos tutelados, como o patrimônio público ou a preservação ambiental.

Diante destes fatos, não são raras as situações de conflitos que se estabelecem entre o Poder Público e aqueles que se utilizam dos imóveis públicos para fazer valer as suas reivindicações, protestos ou necessidades. Tais situações têm causado bastante controvérsia acerca da possibilidade do manejo do desforço imediato, previsto no $\S 1^{\circ}$ do artigo 1.210 do Código Civil, ou ainda, a retomada dos imóveis como corolário do exercício do poder de polícia da Administração Pública, uma vez que ao Poder Público são deferidos poderes-deveres discricionários dotados de autoexecutoriedade e coercibilidade.

Contudo, o poder de polícia, como manifestação do monopólio estatal de violência, deve se pautar nos parâmetros constitucionais, notadamente no devido processo legal, para que sua atuação seja consentânea com a finalidade precípua da Administração Pública, que é a salvaguarda do interesse público primário, ou seja, o bem comum.

O presente artigo objetiva problematizar tal questão, enfatizando, com base emanálise jurisprudencial, istoé, como emprego do método indutivo qualitativo, 
ao lado do hipotético dedutivo, quando é possível afastar a autoexecutoriedade do Poder Público na reintegração, para que a tutela jurisdicional sirva de salvaguarda das garantias constitucionais, em face da retirada das pessoas, caso ela seja necessária ao restabelecimento das finalidades dos bens públicos afetados ou não. Terão destaque neste estudo alguns julgados do Tribunal de Justiça do Estado de São Paulo e do Superior Tribunal de Justiça que enfrentaram a questão, assim como o enunciado recentemente aprovado na I Jornada de Direito Administrativo do Conselho da Justiça Federal.

Pretende-se abordar essa questão controvertida, problematizando sobre a conveniência e oportunidade do manejo de medidas autoexecutórias pelo Estado em situações extremamente delicadas que são as ocupações dos bens públicos, indagando quando é possível o emprego do desforço imediato, pelo poder de polícia, e quando a tutela jurisdicional se faz imprescindível para o melhor equacionamento dos conflitos existentes.

\section{Regime JuRÍdico dOS BENS PÚBLICOS}

Neste ponto será abordado o regime jurídico dos bens que integram o patrimônio das pessoas jurídicas de direito público interno. Com efeito, a definição e o regime legal dos bens públicos são estabelecidos no Capítulo III, do Livro II da Parte Geral do Código Civil de 2002 (artigos 98 a 103), donde se extrai que são considerados bens públicos os bens do domínio nacional pertencentes às pessoas jurídicas de direito público interno.

Em continuação, o Código Civil estabelece a classificação dos bens públicos em: (a) bens de uso comum do povo: os rios, mares, estradas, ruas e praças; (b) bens de uso especial: os edifícios ou terrenos destinados a serviço ou estabelecimento da administração federal, estadual, territorial ou municipal, inclusive os de suas autarquias; e (c) bens dominicais: aqueles que constituem o patrimônio das pessoas jurídicas de direito público, como objeto de direito pessoal, ou real, de cada uma dessas entidades e, salvo disposição de lei em sentido contrário, os bens pertencentes às pessoas jurídicas de direito público a que se tenha dado estrutura de direito privado (artigo 99 e seu parágrafo único).

Os bens de uso comum do povo e os de uso especial são aqueles que integram o domínio público do Estado, porquanto servem a um objetivo público específico (afetados), enquanto os dominicais (ou dominiais) integram o domínio privado do Estado, pois, a despeito de integrarem o patrimônio do ente administrativo, não têm uma finalidade pública definida (desafetados) e, por isso, o Estado exerce verdadeiro direito de propriedade sobre eles. 
fiscalizar e zelar para que sejam mantidas a destinação e o interesse público, o uso e a integridade física dos imóveis pertencentes ao patrimônio público federal.

Os dispositivos invocados no enunciado retrotranscrito, permitem à SPU, por intermédio de seus técnicos credenciados, embargar serviços e obras, aplicar multas e demais sanções previstas em lei e, ainda, requisitar força policial federal e solicitar o necessário auxílio de força pública estadual.

O Enunciado certamente trará mais segurança no agir da administração pública em todos os níveis da federação, porquanto doravante tem-se um standard a ser adotado em defesa do patrimônio imobiliário público, com clara atenção aos interesses em jogo.

\section{CONCLUSÃ̃o}

A Administração Pública exerce sobre todos os bens que compõem o acervo patrimonial estatal a polícia administrativa à vista do mandamento constitucional previsto no artigo 23, inciso I, segundo o qual lhe é imposto o dever de conservar o patrimônio público, sob pena de incorrer em improbidade administrativa, inclusive.

O Estado, tanto na preservação, como na defesa dos seus bens imóveis, deve exercer o poder de polícia, cujo atributo da autoexecutoriedade permite a pronta atuação, independentemente da intervenção jurisdicional, especialmente naquelas situações em que a ocupação de bens redunde num risco de dano grave, seja aos próprios ocupantes, seja ao meio ambiente.

E, nessas circunstâncias, a atuação deve ser rápida e célere, sempre com vistas a evitar um mal maior caso não sejam adotadas as providências necessárias. Mas isso jamais significa que é deferida ao agente público uma "carta branca" para se valer da violência ou arbítrio, haja vista que a atuação da Administração deve sempre estar pautada nos direitos e garantias individuais, especialmente no que concerne ao devido processo legal, assim como na razoabilidade.

Também foi deduzido, da análise jurisprudencial feita, que o manejo do desforço imediato, previsto no artigo 1.210, § $1^{\circ}$, do Código Civil de 2002, é instrumento que também pode e deve ser utilizado pelos entes estatais na defesa do seu patrimônio, desde que sejam adotadas as providências procedimentais e materiais de forma imediata à inequivoca ciência da violação dos bens públicos por particulares, a revelar que a Administração, mesmo em sede de desforço imediato, não pode se descurar da atuação consentânea com a razoabilidade.

Neste ponto, é importante dizer que a atuação estatal, tanto no exercício da polícia administrativa como também na hipótese de desforço imediato, somente é recomendável para aquelas situações em que presente o risco de dano grave, a 
exigir pronta e imediata atuação estatal. É certo, contudo, que é possível o controle judicial posterior da legalidade e razoabilidade dos atos, porventura, praticados, mas é mais recomendável acionar controles preventivos e concomitantes, sendo inclusive eficaz o controle social da Administração.

Todavia, naquelas situações em que não se vislumbra risco à ordem pública, ou a qualquer das partes, ou ausente ainda o risco de dano ambiental grave e irreversível, ou, principalmente, naquelas ocupações multitudinárias e consolidadas pelo decurso de tempo diante da inação estatal, é de todo prudente que a Administração Pública se valha da intervenção jurisdicional para que os interesses contrapostos sejam tutelados de forma justa e consentânea com as garantias constitucionais existentes.

Verificou-se que isso, longe de negar o poder da Administração, afirma o próprio direito estatal de fazer valer sua pretensão num ambiente de maior imparcialidade e de fiscalização judicial do interesse público em jogo, dada a necessidade de sopesamento de inúmeros fatores, garantindo a justiça e a lisura do pronunciamento estatal no que concerne à conservação dos bens públicos, sem deixar de ouvir e considerar o interesse particular na decisão jurisdicional.

O tema aqui abordado é de tamanha relevância que ensejou a aprovação de enunciado específico na I Jornada de Direito Administrativo, que se alinha perfeitamente ao entendimento aqui adotado, estabelecendo-se um padrão de agora em diante no tratamento da matéria. Segundo o verbete, permite-se o desforço imediato à Administração Pública, desde que o faça logo, observada a razoabilidade e o respeito aos valores constitucionais quando da manutenção ou restituição do imóvel.

Por isso, conclui-se que, diante da diversidade das circunstâncias que os casos concretos podem impor, a adoção de uma ou de outra postura pelo Estado deverá sempre ter como norte aquilo que melhor atender ao interesse público, sem que se descure dos direitos e garantias individuais, tendo em vista a preocupação maior com a tutela da dignidade humana, em hard cases.

\section{REFERÊNCIAS}

ALEXY, Robert. Teoria de los derechos fundamentales. Trad. Ernesto Grazón Valdés. Madrid: Centro de Estudios Políticos y Constitucionales, 2002.

BANDEIRA DE MELLO, Celso Antônio. Curso de Direito Administrativo. São Paulo: Malheiros, 2008.

BANDEIRA DE MELLO, Celso Antônio. Discricionariedade e Controle Jurisdicional. 2. ed. 10. tir. São Paulo: Malheiros, 2010.

HACHEM, Daniel Wunder. Principio constitucional da supremacia do interesse público. Curitiba: Dissertação UFPR, 2011. 
JUSTEN FILHO, Marçal. Curso de Direito Administrativo. 12. ed. São Paulo: Revista dos Tribunais, 2016.

LIEBMAN; Enrico Tullio. Manual de Direito Processual Civil. Rio de Janeiro: Forense, 1984.v. 1.

MONTEIRO, Washington de Barros. Curso de Direito Civil. Direito das coisas. São Paulo: Saraiva, 2003. v. 3.

NOHARA, Irene Patrícia. Direito Administrativo. 7. ed. São Paulo: Atlas, 2017.

NOHARA, Irene Patrícia. Reflexões críticas acerca da tentativa de desconstrução do sentido da supremacia do interesse público no Direito Administrativo. In: DI PIETRO, Maria Sylvia Zanella; RIBEIRO, Carlos Vinícius Alves (Coord.). Supremacia do Interesse Público e Outros Temas Relevantes do Direito Administrativo. São Paulo: Atlas, 2010.

SARLET, Ingo Wolfgang. Dignidade da Pessoa Humana e Direitos Fundamentais na Constituição de 1988. Porto Alegre: Livraria do Advogado, 2006.

\section{Pesquisas do Editorial}

\section{Veja também Doutrinas relacionadas ao tema}

- Ação civil pública: defesa do patrimônio público e da moralidade administrativa, de Nilo Spinola Salgado Filho e Wallace Paiva Martins Júnior - RT 735/161-172 (DTR|2011|2531); e

- Solução extrajudicial de conflitos na proteção do patrimônio público e da probidade administrativa, de Cláudio Smirne Diniz e Eduardo Cambi - RT 994/49-69 (DTR|2018|18305). 
